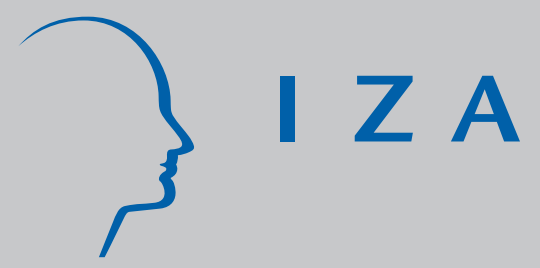

IZA DP No. 1087

The Political Economy of Social Exclusion with Implications for Immigration Policy

Mark Gradstein

Maurice Schiff

March 2004 


\title{
The Political Economy of Social Exclusion with Implications for Immigration Policy
}

\author{
Mark Gradstein \\ Ben-Gurion University, \\ CEPR and CESifo \\ Maurice Schiff \\ World Bank and IZA Bonn

\section{Discussion Paper No. 1087 \\ March 2004} \\ IZA \\ P.O. Box 7240 \\ 53072 Bonn \\ Germany \\ Phone: +49-228-3894-0 \\ Fax: +49-228-3894-180 \\ Email: iza@iza.org
}

\begin{abstract}
Any opinions expressed here are those of the author(s) and not those of the institute. Research disseminated by IZA may include views on policy, but the institute itself takes no institutional policy positions.
\end{abstract}

The Institute for the Study of Labor (IZA) in Bonn is a local and virtual international research center and a place of communication between science, politics and business. IZA is an independent nonprofit company supported by Deutsche Post World Net. The center is associated with the University of Bonn and offers a stimulating research environment through its research networks, research support, and visitors and doctoral programs. IZA engages in (i) original and internationally competitive research in all fields of labor economics, (ii) development of policy concepts, and (iii) dissemination of research results and concepts to the interested public.

IZA Discussion Papers often represent preliminary work and are circulated to encourage discussion. Citation of such a paper should account for its provisional character. A revised version may be available on the IZA website (www.iza.org) or directly from the author. 
IZA Discussion Paper No. 1087

March 2004

\section{ABSTRACT}

\section{The Political Economy of Social Exclusion with Implications for Immigration Policy}

Minorities, such as ethnic and immigration groups, have often been subject to exclusion through labor market discrimination, residential and employment segregation policies, business ownership regulations, restrictions on political participation, access to public services and more. This paper studies the dynamics of minority exclusion. From the viewpoint of the dominant majority, the exclusion decision balances the motive to redistribute income in its favor and the interest in avoiding potential civic unrest or even violent confrontation with the minority by allowing inclusion of some of its members. The analysis also has implications for immigration policies which have to take this group dynamics into account.

JEL Classification: $\quad$ D74, H41, I20, J61

Keywords: $\quad$ social exclusion, dynamics, immigration policy

Corresponding author:

Maurice Schiff

Development Research Group

The World Bank

Mailstop No. MC3-303

$1818 \mathrm{H}$. St. NW

Washington DC 20433

Tel.: +1 2024737963

Fax: +1 2025221159

Email: mschiff@worldbank.org 


\section{Introduction}

Minority groups have often been subject to exclusion and discrimination, manifested through labor market discrimination, laws and policies restricting residence and business opportunities, limits on political participation, restrictions on access to public services such as education, and others. ${ }^{1}$ One important case of such policies pertains to ethnic exclusion, notorious examples of which include discrimination against ethnic minorities in AustroHungary and other parts of Europe in the first half of the twentieth century, ${ }^{2}$ and against indigenous populations in colonized parts of the world by Europeans (such as in the US, Australia, South Africa and Latin America).

A frequent outcome of discriminatory practices has been an extremely unequal distribution of resources across ethnic groups. ${ }^{3}$ As described in more detail below, in some countries, ethnicity and income have been strongly correlated. Moreover, a substantial part of this correlation can be explained by differences in access to publicly provided goods and services such as education. ${ }^{4}$

Extreme disparities in wealth and access to resources among population groups have often led to violent confrontations. Gurr, 1993, contains a compilation of records on all civil conflicts in the post World War II period. It reports that a significant fraction of these had an ethnic component. Frictions, which amount to less than full fledged civil war but still entail violent elements, are even more common. In contrast, many countries have adopted an ever more inclusive attitude toward minority groups. This, for example, has been the case in several countries in the Americas with regard to the native populations, and in the US with regard to the various immigrant groups, where first European immigrants (Irish, Italian, East European), then - and only after a non-trivial struggle - Asian immigrants, and subsequently African Americans were granted equal rights, see Jacobson, 1998.

More recently, Europe - which historically used to be a source of out-migration - has 
become exposed to large waves of immigration from developing countries. The proportion of foreign-born population in some countries such as Austria, the Netherlands, and Sweden now exceeds 10 percent - a figure comparable or even exceeding that in the United States, whereas in Switzerland this proportion is almost twice as large (OECD, Trends in International Migration, 2004). Often, the immigrants are poorer and socially distinct from the natives, and labor markets effects as well as social and cultural frictions have led to consideration of stricter immigration and asylum policies; but also of policies designed to promote cultural assimilation. ${ }^{5}$

This paper purports to construct a simple model of the dynamics of inclusion. In the model, the incentive to exclude a minority by erecting barriers to their egalitarian participation comes from the majority's motive to redistribute income in its favor. The excluded minority can, however, initiate civic unrest or even launch a rebellion, which is the expected outcome when income differentials between the groups are large enough. ${ }^{6}$ Although a rebellion is destructive for the economy and, in particular, entails a deadweight loss, it may still be attractive for the minority as a means of expropriating part of the majority's income. ${ }^{7}$ The threat of a rebellion can only be alleviated by lowering exclusion barriers. We characterize the intertemporal evolution of such an economy, along with its steady state. One of the main implications of this analysis is that, at equilibrium, the degrees of exclusion and income inequality are positively related to the likelihood of a rebellion and social unrest.

Issues addressed in this paper have been brought up repeatedly by social scientists. Influential political scientists such as Gellner, 1983, and Greenfeld, 1992, theorize that ethnic conflicts are more likely to erupt when barriers to upward mobility of minority groups exist. More recently, there has also been growing attention to this topic among economists. Thus, Glaeser and Shleifer, 2002, study political motives to engage in inefficient appropriation from 
an opposite ethnic group so as to drive its members out of a jurisdiction, thus increasing chances of reelection. Their view of ethnic interaction is different from the one presented in this paper, where the main motivation is redistribution from the minority to the majority group, making exit of the former undesirable from the viewpoint of the latter. Rapoport and Weiss, 2001, study social integration focusing on the minority's perspective. Caselli and Coleman, 2002, focus on ethnic conflict and relate its incidence to the cultural distance between groups. While in their model the costs of minority integration are exogenously given and determine the likelihood of conflict occurrence, here the integration process is endogenized.

Whereas the above papers are essentially static, Bertocchi and Spagat, 2001, consider a conceptually related dynamic framework. The looming of rebellion in their model induces extension of a voting franchise as a way for the rich to gradually co-opt the poor. In contrast, in this paper, the co-optation of the poor is not a political but rather a social and cultural issue, i.e., by allowing the minority to culturally assimilate by making access to public education available to it. Indeed, the main novelty of this paper is to study how and under what conditions social exclusion can be used for economic gains as opposed to the circumstances under which social integration will prevail. One implication of the analytical framework is that immigration policies may be constructed so as to take into consideration the above described dynamics.

The paper is organized as follows. The next section describes the basic setup. Section 3 analyzes, as a benchmark, a special case which only allows for perfect exclusion and inclusion. A systematic analysis of gradual inclusion is then presented in Section 4. Section 5 relates its implications to empirical findings and discusses, in sub-section 5.2, implications for immigration policies. Section 6 concludes with brief remarks. 


\section{Basic Framework}

Consider an economy in discrete time $t$ populated by a continuum of non-overlapping households, each consisting of a parent and child. The population is divided into two internally homogeneous groups, indexed $g=1,2$, and referred to as a majority (group 1) and a minority (group 2). $N_{t}$ and $n_{t}=1-N_{t}$ will denote the respective size of the two groups in period $t$. The income of an individual from group $g$ in period $t$ is denoted $y_{g t}$, the level of human capital is $h_{g t}$ and her consumption is $c_{g t}$. The initial human capital and income levels are exogenously given, and those of the majority members exceed the corresponding levels of the minority members. As will become clear, it is not the relative size of the groups that matters for the distinction, but their political influence. The latter is assumed to be determined by income, or, equivalently, by education level. Thus, group 1 is decisive because its education and material wealth are assumed large enough. Although nothing in the model prevents a broader view, the most straightforward interpretation of the majorityminority distinction here is in terms of ethnic groups. ${ }^{8}$

Income taxes are used to generate human capital investment, so that $T$ denotes the tax rate in period $t$ and $T Y_{t}$, where $Y_{t}$ is the aggregate economy's income, denotes the proceeds from the tax. The assumption of an exogenously given, intertemporally fixed, tax rate enables us to focus attention on exclusion policies. ${ }^{9}$ Tax revenues are assumed to be used to build schools for the majority. Assuming that each dollar generates one unit of education services for members of the next-period majority - the amount of education provided to each such member in period $t+1$ is $T Y_{t} / N_{t+1}$. Thus, education services provided through taxes are perceived as a club good benefiting solely the majority members. One reason why exclusion from schooling could be beneficial for the majority is that this way its political power is not diluted. ${ }^{10}$

Human capital investment generates next-period income,

$$
y_{I t+1}=A\left(T Y_{t} / N_{t+1}\right)^{\alpha}, A>0,0<\alpha<1
$$


and net income is used for consumption,

$$
c_{l t}=y_{l t}(1-T)
$$

The minority has to provide its own education using after-tax income. Letting $h_{2 t_{+1}}$ denote the amount of education available to each minority member, her next-period income is

$$
y_{2 t+1}=A h_{2 t+1}^{\alpha}
$$

Because the minority members still have to pay taxes, their budget constraints are as follows:

$$
c_{2 t}+h_{2 t+1}=y_{2 t}(1-T)
$$

The individual utility of the majority group members is derived from current consumption and from their child's income and is assumed logarithmic:

$$
U\left(c_{1 t}, y_{1 t+1}\right)=\ln \left(c_{1 t}\right)+\ln \left(y_{l t+1}\right)=\ln \left(y_{l t}(1-T)\right)+\ln \left(A\left(T Y_{t} / N_{t+1}\right)^{\alpha}\right)
$$

where the relative weights are assumed identical for simplicity and the last part is obtained after substituting (1) and (2).

The particular assumption on the nature of parental altruism embodies the "warm glow" motive for intergenerational transfers. It simplifies the analysis by rendering the effect of children actions irrelevant from a parental perspective.

The preferences of the minority group members are similar, but include in addition potential disutility as a result of switching from consuming education along with the minority members to doing so together with the majority group. This utility cost consists of two components. One component, denoted $E_{t}$, is the level of exclusion in period $t$, set by the majority members. It captures the level of access to majority schools and the extent of their availability for the minority members, and is directly related to the degree of discrimination against the minority members. ${ }^{11}$ It is a policy variable, endogenously determined.

Another component is an exogenous cost of $\phi_{i}$, assumed to be distributed in period $t$ according to a cdf $F_{t}$, where the initial distribution $F_{0}$ is exogenously given. The parameter $\phi_{i}$, can be interpreted as the social cost of integration into the majority club. These costs may 
depend on the cultural distance between the majority and the minority, for example. Differences in integration costs across individuals or, especially, across groups is evident when one examines them in the context of immigrant ethnic groups. Thus, in the US, extensive research suggests that various groups, such as Asians as well as Europeans (Irish, Polish, Italians) were not always perceived as belonging to the white majority. But while for the latter group the recognition process, if not entirely smooth, was relatively quick and without extreme displays of animosity, for Asian immigrants it was much more painful. Because naturalization and citizenship in the United States since the late nineteenth century crucially hinged upon legitimacy of claims to white racial identity, restrictive racial laws affected that group severely. Asian immigrants had to face restrictions on marriage with native whites, business ownership, housing, some jobs, schools, railway cars, and other settings (Jacobson, 1998). ${ }^{12}$

Because integration costs represent cultural traits, it is natural to assume that they are transmitted across generations (hence, the subscript $t$ is omitted). Thus, the minority dynasties are assumed to differ with regard to the ease of their integration in the majority schools. With reference to the episodes of immigration to the US, for example, immigrants of Irish origins might have had easier times getting integrated than those from Italy (at least from the language point of view), while integration for the latter was less costly than for Asian immigrants (partly also linguistically but mostly culturally).

The utility level of those minority members who choose not to integrate is

$U^{0}\left(c_{2 t}, y_{2 t+1}\right)=\ln \left(c_{2 t}\right)+\ln \left(y_{2 t+1}\right)=\ln \left(y_{2 t}(1-T)-h_{2 t+1}\right)+\ln \left(A h_{2 t+1}{ }^{\alpha}\right)$

where the last part is obtained by substituting (3) and (4).

The utility of those who prefer integration is as follows: ${ }^{13}$

$U^{I}\left(c_{2 t}, y_{2 t+1}\right)=\ln \left(c_{2 t}\right)-E_{t} \phi_{i}+\ln \left(y_{2 t+1}\right)=\ln \left(y_{2 t}(1-T)\right)-E_{t} \phi_{i}+\ln \left(A\left(T Y_{t} / N_{t+1}\right)^{\alpha}\right)$

All decisions in the model are made by the parents. 


\section{Exclusion and inclusion}

To help understand some of the basic principles behind the results, we begin with the comparison of extreme cases of perfect inclusion and perfect exclusion in the absence of rebellion. Under perfect exclusion, there is no mobility across the groups, so that $N_{0}$ is the majority size in all periods. In this case, the minority parents decide how much to invest in education. Under perfect inclusion, there is no distinction among the individuals and, in particular, the amount of human capital received by all of them is $T Y_{t}$.

Perfect exclusion, $E_{t} i s$ very large. In this case, there will be no integration. Given a period $t$ tax rate, the minority members determine their human capital investment so as to maximize utility. As is shown in the appendix, the majority is better off relative to the minority with regard to present consumption, future income, and the growth rate. The reason, of course, is that the minority is forced to finance the education of the majority as well as its own, which testifies to the exploitative nature of exclusion.

Perfect inclusion, $E_{t}=0$. With perfect inclusion, all minority members choose to immediately integrate within the majority club. ${ }^{14}$ The equilibrium analysis and its comparison with the case of perfect exclusion, presented in more detail in the appendix, reveal that the minority benefits, somewhat at the expense of the majority, from inclusion; but the latter may improve the economy's growth prospects overall. Moreover, better growth prospects also imply that aggregate welfare is higher under inclusion. Specifically, the following is obtained:

Proposition 1. The majority is better off while the minority is worse off under perfect exclusion in the absence of rebellion than under inclusion. Given that the tax rate is large 
enough, the average steady state income is higher under inclusion. ${ }^{15}$

\section{Gradual inclusion}

\subsection{Model}

In the previous model, exclusion of the minority is the preferred strategy for the majority, despite the overall advantages that an inclusive economy confers. For the purposes of studying the dynamics of exclusion, we assume that initially, in period 0 , the level of exclusion is infinitely high, so that none of the minority group members can integrate. ${ }^{16}$

An important reason why perfect exclusion may not be sustainable in the future is because of a potential threat posed by the minority. There are several interpretations of such threats. One of them is the threat of secession, which is especially viable when the minority is residentially concentrated. Another "strategy" for the minority could be emigration, see Glaeser and Shleifer, 2002, incorporating this important element. In this paper, in order to focus on other issues, this is initially precluded by assuming that the migration costs are excessively large. Finally, the interpretation that is pursued here is that of an insurgency.

More specifically, we assume that if the minority decides to launch a rebellion instead of peacefully accumulating human capital, a fraction $z$ of the output $A\left(T Y_{t}\right)^{\alpha}$ survives and a share $1-z$ gets destroyed. ${ }^{17}$ Specifically, we assume that, if a rebellion is launched, the share of output left at the hands of the majority is $R\left(N_{t+1}\right)$ whereas the share of the minority, part of which has been expropriated from the majority, is $R\left(n_{t+1}\right)$, where $R^{\prime}, R^{\prime \prime}>0, R(0)=0, R(1)=$ 1. In addition, we can write $z=z\left(N_{t+1}\right)=R\left(N_{t+1}\right)+R\left(n_{t+1}\right)=R\left(N_{t+1}\right)+R\left(1-N_{t+1}\right)$, z' $>0, \mathrm{z}(1)$ $=1$; for instance, $R\left(N_{t+1}\right)=N_{t+1}^{2}$ and $R\left(n_{t+1}\right)=n_{t+1}^{2}$ constitutes a plausible example.

This, in particular, implies that a rebellion entails a deadweight loss in the course of which a part of output - which is an increasing function of the intensity of the conflict, captured by the share of the minority - is lost; and also that the majority is always able to 
capture a larger share of the output. For $R\left(N_{t+1}\right)=N_{t+1}^{2}$ and $R\left(n_{t+1}\right)=n_{t+1}^{2}, z\left(N_{t+1}\right)=N_{t+1}^{2}+$ $\left(1-N_{t+1}\right)^{2}$, which - as $N_{t+1}>1 / 2$ - rises with $N_{t+1}$. In other words, the deadweight loss, $1-z$, increases with the size of the minority. We also assume that the appropriated share of the output is equally shared among the members of a group, which - along with the assumed properties of $R$ - implies that the majority retains a larger share of output per member. ${ }^{18}$

For analytical simplicity, we will assume that in the case of rebellion, minority integration is no longer possible so that rebellion and peaceful accumulation with integration are mutually exclusive alternatives. ${ }^{19}$ Then, if rebellion takes place, the respective composition of the two groups remains unchanged $\left(N_{t+1}=N_{t}, n_{t+1}=n_{t}\right)$, so that the respective utility levels of the members of the two groups are as follows:

$$
\begin{aligned}
& U_{1}=\ln \left((1-T) y_{1 t}\right)+\ln \left\{A\left(T Y_{t}\right)^{\alpha} R\left(N_{t}\right) / N_{t}\right\} \\
& U_{2}=\ln \left((1-T) y_{2 t}\right)+\ln \left\{A\left(T Y_{t}\right)^{\alpha} R\left(n_{t}\right) / n_{t}\right\}
\end{aligned}
$$

When exclusion is imperfect and given that integration is costly as we have assumed is the case, the exclusion decision affects the willingness of the minority members to integrate. We assume that the integration decision is irreversible and has immediate consequences for one's child, who inherits parental characteristics and becomes fully immersed in the majority culture.

The sequence of events in each period is as follows. First, the majority decides on the degree of exclusion, $E_{t}$. Then the minority decides (by a majority vote) whether to launch a rebellion or to peacefully accumulate human capital. The latter decision is assumed binding for the period's duration, through a signed agreement with the majority, for example. After that, in the case of peaceful accumulation, minority members decide whether or not to integrate, depending on their individual assimilation costs, and remaining minority members decide on the level of human capital investment, and incomes are thus determined. The 
equilibrium consists of the above decisions, which are mutually consistent and where the agents correctly anticipate future actions.

\subsection{The dynamics of exclusion: equilibrium analysis}

We examine first the integration decisions by the minority members under peaceful accumulation of human capital. The optimal level of human capital investment for the minority along with their respective utility levels are shown in the appendix.

Clearly, only minority members with low integration costs will choose to integrate. Specifically, the condition is $U^{\mathrm{I}}>U^{0}$, or:

$\left(y_{2 t}(1-T)\right)-E_{t} \phi_{i}+\ln \left[A\left(T Y_{t} / N_{t+1}\right)^{\alpha}\right]>\ln \left(y_{2 t}(1-T) /(1+\alpha)\right)+\ln \left\{A\left[\alpha y_{2 t}(1-T) /(1+\alpha)\right]^{\alpha}\right\}$

which can be written as

$$
\phi_{i}<\phi_{t}{ }^{*}=\left\{\ln \left(T Y_{t} / N_{t+1}\right)^{\alpha}+\ln (1+\alpha)-\ln \left[\alpha y_{2 t}(1-T) /(1+\alpha)\right]^{\alpha}\right\} / E_{t}
$$

and the equilibrium size of the next-period majority is given by:

$$
N_{t+1}=N_{t}+F_{t}\left(\phi_{t}^{*}\right)
$$

Since $\phi_{t}{ }^{*}$ is a decreasing function of $N_{t+1}$, the equilibrium in each period is uniquely defined. Moreover, differentiation of (8) and (9) reveals that the equilibrium size of the majority is an increasing function of the tax rate and of the ratio between the average economy's income and the income of the minority members, $Y_{t} / y_{2 t}$; and that it is a decreasing function of the degree of exclusion, $E_{t}$.

We now examine the rebellion decision by the minority, beginning with those minority members who do not plan to integrate, $\phi_{i}>\phi_{t}{ }^{*}$, where $\phi_{t}{ }^{*}$ is given by (8). Such individuals prefer rebellion if and only if

$\ln \left((1-T) y_{2 t}\right)+\ln \left\{\mathrm{A}\left(T Y_{t}\right)^{\alpha} R\left(n_{t}\right) / n_{t}\right\}>\ln \left(y_{2 t}(1-T) /(1+\alpha)\right)+\ln \left\{A\left[\alpha y_{2 t}(1-T) /(1+\alpha)\right]^{\alpha}\right\}$, or rearranging terms, whenever 


$$
(1+\alpha)^{1+\alpha}\left(T Y_{t} /(1-T) \alpha y_{2 t}\right)^{\alpha} R\left(n_{t}\right) / n_{t}>1
$$

In contrast, minority members who plan to integrate, $\phi_{i}<\phi_{t}{ }^{*}$, prefer rebellion provided that

$\ln \left(y_{2 t}(1-T)\right)-E_{t} \phi_{i}+\ln \left[A\left(T Y_{t} / N_{t+1}\right)^{\alpha}\right]<\ln \left(y_{2 t}(1-T)\right)+\ln \left\{\mathrm{A}\left(T Y_{t}\right)^{\alpha} R\left(n_{t}\right) / n_{t}\right\}$,

or, $\ln \left[\left(n_{t} / N_{t+l} R\left(n_{t}\right)\right)^{\alpha}\right]<E_{t} \phi_{i}$

Figure 1 illustrates these conditions depicting the utility levels, as a function of the integration costs, of the minority members who plan to remain such under peaceful accumulation $\left(U^{0}\right)$, those who plan to integrate into the majority $\left(U^{0}\right)$, and their utility under rebellion $\left(U^{R}\right)$. It is drawn assuming that the rebellion option dominates that of a peaceful accumulation from the minority's perspective.

\section{INSERT FIGURE 1 HERE}

Recall that $\phi_{t}^{*}$ is the level of integration costs for which a minority member is indifferent between remaining a minority member and integrating. Note that the utility level $U^{I}$ is drawn for a given degree of exclusion, say $E^{\prime}$, which is chosen so that half of the minority members fare better with integration rather than under rebellion. Thus, given $E^{\prime}, F_{t}\left(\phi_{t}^{*}\right)$ of the minority members, $F_{t}\left(\phi_{t}^{*}\right)>1 / 2$, choose to integrate. $F_{t}^{-1}(1 / 2)$ is the cost level such that half of the minority members prefer integration to rebellion. Clearly, integration of more than half of the minority members is needed to alleviate the rebellion threat. If $U^{0}>U^{R}$, then the majority would choose full exclusion, because the minority always fares better under peaceful accumulation.

Note that - from (10) - the larger is the period $t$ income gap between the ethnic groups the more viable rebellion becomes, hence the more inclusive society has to be in order to alleviate the threat. Moreover, the threat of rebellion increases with the relative size of the minority group and with the tax rate. Clearly, if a minority member with a given integration 
cost prefers rebellion, all those with higher costs prefer rebellion too; and if a given member prefers peaceful accumulation, those with lower integration costs prefer it as well. Also note how the exclusion barriers $E_{t}$ affects the likelihood of a rebellion: for a given distribution of income the lower $E_{t}$ the more minority members choose to integrate, which causes the coalition of support for a rebellion to shrink. An empirical implication of this consideration is that rebellions are more likely to occur, ceteris paribus, in societies which practice a high degree of exclusion.

To sum up,

Proposition 2. The individual support for a rebellion is inversely related to the integration costs. Moreover, the larger is the income differential across the groups, the higher is the tax rate and the larger the minority group, the more attractive rebellion is for the latter; and the smaller the degree of exclusion, the larger is the number of minority members who plan to integrate, thus weakening the coalition of support for a rebellion.

When income differences between the two groups are high enough so that rebellion becomes viable, an exclusion policy that ensures integration of more than one half of the minority members is the only way to prevent it (since decisions in the minority group are made by majority vote).

Income divergence over time between the minority and the majority implies that rebellion incentives increase; thus, to avoid eventual rebellion, exclusion barriers would necessarily have to gradually decrease over time. When will it be in the best interest of the majority to do so?

The condition is

$$
\ln \left((1-T) y_{1 t}\right)+\ln \left\{A\left(T Y_{t}\right)^{\alpha} R\left(N_{t}\right) / N_{t}\right\}<\ln \left((1-T) y_{1 t}\right)+\ln \left\{A\left(T Y_{t}\right)^{\alpha} / N_{t+1}\right\}
$$

or, $R\left(N_{t}\right)<N_{t} / N_{t+1}$; that is - recalling the assumptions on the rebellion technology - when the 
majority is small enough.

\subsection{Steady-state}

The steady state is characterized by the relative size of the majority group $\left(N^{*}\right)$ and the minority group $\left(1-N^{*}\right)$ along with the respective income levels in the two groups $\left(y_{1}{ }^{*}\right.$ and $\left.y_{2}{ }^{*}\right)$ and the level of exclusion $\left(E^{*}\right)$, such that the minority does not find it in its best interest to launch a rebellion, nor do minority members want to further integrate; the respective income levels do not change over time; and the majority is not interested in lowering the level of exclusion.

Suppose that, while initial inequality is relatively low, the initial minority group size is large enough indicating that it is interested in rebellion; and the small size of the majority implies that it prefers avoiding the rebellion. Gradual lowering of exclusion barriers indicated in the above analysis alongside with the monotonic decrease in the size of the minority group over time imply existence of a steady state which is characterized as follows: ${ }^{20}$

$y_{2}{ }^{*}=A^{1 /(1-\alpha)}[\alpha(1-T) /(1+\alpha)]^{\alpha /(1-\alpha)}, y_{1}{ }^{*}=A\left(T Y^{*} N^{*}\right)^{\alpha}$, with $Y^{*}=N^{*} y_{1}{ }^{*}+\left(1-N^{*}\right) y_{2}{ }^{*}$

and

$$
(1+\alpha)^{1+\alpha}\left(Y^{*} / y_{2}^{*}\right)^{\alpha} R\left(n^{*}\right) / n^{*}=1
$$

which is the indifference condition for the minority members between rebellion and peaceful accumulation; the level of exclusion is determined then from (8) and (9).

There is also an additional possibility with quite contrasting consequences. Thus, if the initial level of inequality is large, the majority may not be interested in lowering exclusion barriers. Then rebellion will take place. Once it has taken place and part of the output has been destroyed and part of the majority's income has been expropriated by the minority, both groups return to peaceful accumulation. Because the majority is still able to capture a larger 
share of income, the widening income gap over time between the majority and the minority may make eventual rebellion once again inevitable, and so on. Thus, when the initial inequality is high, exclusion barriers may not be reduced, and the economy will oscillate between periods of peaceful accumulation and violent rebellion.

To sum up,

Proposition 3. If income differentials are initially low, exclusion barriers will be gradually reduced leading to the integration of part of the minority and peaceful accumulation over time. The economy converges to a steady state characterized by a small pocket of poor minority (having high integration costs and therefore reluctant to be fully integrated). If, however, initial inequality is high, peaceful accommodation may be disadvantageous for the majority, which then is prepared to bear the consequences of violent confrontation. In this case, the economy could oscillate between periods of peaceful accumulation and violent rebellion by the minority.

While indicating two steady states to which the economy can converge, this result implies that, in equilibrium, the degree of exclusion and violent confrontations among ethnic groups are positively related. Because, as stated in Proposition 1, with diminishing returns to scale inclusion is beneficial for the entire population in the long run, the non-violent steady state with inclusion dominates the one with exclusion.

\section{Discussion}

\subsection{Empirical evidence}

Here existing empirical evidence is reviewed which is consistent with the model's implications. One important source of information is the emerging literature on the onset of civil wars. Thus, Collier and Hoeffler, 2001, show that the likelihood of a civil war is positively related to ethnolinguistic polarization and to the relative size of the minority group, which fits well the 
proposed framework. The paper Reynal-Querol, 2001, goes one step further, claiming that ethnic tensions are more important in this regard than religious differences. More importantly, it argues that the political framework is an important intermediary in the relationship between ethnicity and violent conflict; specifically, democracy in the form of civil rights is a mitigating factor in this regard. These results are also related to Easterly and Levine, 1997, who claim that ethnic heterogeneity could be a detrimental factor for economic growth, especially in Africa, and to Easterly, 2001, 2002, who similarly detects a positive relationship between ethnic heterogeneity and insurgency, noting that quality of institutions, such as rule of law and freedom from expropriation, tend to reduce violence.

Another related branch of the literature studies the causes of civil unrest. DiPasquale and Glaeser, 1998, examine the determinants of rioting, both cross-nationally and in the US. In four countries with the highest number of riots in the period 1960-85 in their sample, India, the US, South Africa, and Pakistan, the ethnic/racial element was of overriding importance. Ethnic heterogeneity was found to be a significant predictor of rioting in all their regressions.

Another relevant group of studies is devoted to the consequences of residential segregation, in particular for the distribution of income across population groups. ${ }^{21}$ For example, Cutler and Glaeser, 1997, discern substantial negative effects for the black population of such segregation in the US. In their study, one standard deviation increase in segregation reduces the relative earnings of blacks by 7-9 percent. Similar findings have been reported in international contexts as well, see Patrinos, 1994, for a review. Specific examples where wage differentials between ethnic groups are significant even when controlling for occupation, education and other background variables include caste discrimination in the labor market in India, discrimination against blacks in the past in South Africa, against indigenous populations in many countries colonized by Europeans, and against ethnic minorities in China.

For example, it is found that, other things being equal, being indigenous in Bolivia 
increases the probability of being poor by 16 percent; in Guatemala, access to education, health care services, water and sanitation, and jobs is likewise shown to significantly differ across indigenous and non-indigenous groups. It is hypothesized that, among other factors, residential segregation plays a role in perpetuating these inequalities. Moreover, more closely related to this paper's theory is the argument that schooling is a major impediment to a more complete integration of minorities in several Latin American countries, such as Bolivia and Guatemala (on this see also Psacharopoulos, 1993). Specifically, using Spanish as the language of instruction makes education too costly for indigenous populations, a vast majority of which is concentrated in rural areas with difficulties of access to schooling. ${ }^{22}$

A striking example is presented by the experience of South African apartheid, where race and income have been particularly close correlates. ${ }^{23}$ By the end of the apartheid era, Africans made up $98 \%$ of the poorest quintile and only slightly more than $10 \%$ of the richest, whereas whites had no one among the poorest quintile and made up more than $75 \%$ of the richest quintile. $^{24}$ The adult illiteracy rate among Africans exceeded those in neighboring countries by between 10 and 30 percentage points, and their life expectancy was also considerably lower. The UN human development index for the white population ranked 19 in the world in 1992, whereas for Africans it was 100 ranks below, between Swaziland and Lesotho (ranked 119 in 1992). ${ }^{25}$ Inequalities in access to and use of services, durable goods, employment, and wages were similarly very large.

A report by The Economist (February 21, 2004) describes the rise of a new ethnic politics in Latin America, particularly in the Andean countries of Bolivia, Ecuador and Peru, where "... the emergence of newly assertive Indian movements ... is undeniable." This emergence has several root causes. The main reported ones are the indigenous populations' relative poverty and extreme poverty, and their lower access to basic services, including education. For instance, in Ecuador, 18 percent of those aged 18 to 25 benefit from full-time 
education while the figure for indigenous people is mere 1 percent. Moreover, indigenous people constitute a large majority of those killed in recent civil wars in Guatemala and Peru. The increased threat of rebellion and success of indigenous movements has resulted in their increased participation in the political process, aided also by the spread of democracy. For instance, out of a total of 130, Bolivia has now 50 indigenous deputies in the lower house of Congress. Most Latin American governments also signed ILO's Convention 169 which guarantees indigenous people equal rights, access to health and education, respect for their culture and institutions, and participation in the formulation of policies that affect them directly.

\subsection{Implications for immigration policies}

Host countries typically impose a variety of barriers on immigration (Mattoo and Carzaniga, 2003). Some barriers deal with immigration issues such as quantitative restrictions, border controls, work permits (often attached to specific jobs), economic needs tests, wage parity requirements which erode the advantage of hiring foreigners, and more. Other barriers relate to the discriminatory treatment of foreign service providers such as preferences in government procurement granted to domestic service providers and lack of recognition of foreign training, qualifications and/or experience.

The analysis provided in this paper has implications for host countries' immigration policies, specifically, making it necessary to consider immigration policies in conjunction with social inclusion policies. For suppose that the immigrants belong to the minority ethnic group. ${ }^{26}$ Immigration, by increasing the size of the excluded minority, makes the majority better off. On the other hand, as stated in Proposition 3, the larger the minority group, the more attractive rebellion becomes. Thus, a more open immigration policy invites accommodation in the form of social inclusion so as to alleviate the rebellion threat. Casual 
observation suggests that countries that are more accommodating in terms of social integration (most Western democracies) are also the ones that have pursued more open immigration policies.

An additional factor is the effect of immigration on wages. Thus, assume that the majority consists of high-skilled labor and the minority and the immigrants consist of low or unskilled labor. Under the small open economy assumption, immigration has no impact on wages as long as the host economy remains in the cone of diversification. However, as immigration increases, the host economy will eventually move outside the cone of diversification, and minority wages will fall. As stated in Proposition 3, the likelihood of rebellion increases with the income differential between the majority and the minority, again resulting in a reduction in the majority's welfare. This then constitutes yet another consideration for the majority to impose immigration restrictions.

\section{Concluding remarks}

This paper examines the political economy of social exclusion. From the majority viewpoint, exclusion of the minority allows redistribution of income in its favor, but carries the danger of a violent rebellion. As incentives for the latter grow over time because of increased deprivation of the minority, exclusion barriers may be gradually reduced. One interesting result revealed in the dynamic analysis is the possibility of multiple steady states related to the level of income inequality and to the degree of exclusion. Specifically, if initial levels of exclusion and inequality are high the economy may oscillate between periods of rebellion and peaceful accumulation, whereas if these levels are low, rebellion will be avoided, and the economy will peacefully converge to a steady state with higher income.

Many important issues are left for further investigation. One of them is the impact on the inclusion policies of imperfect immigrant border controls. Another is the effect of increased 
intensity of interaction between the majority and the minority (as a result of urbanization, for example) on the likelihood of rebellion and on exclusion policies. Yet another issue is the effect of media penetration and improved means of communication on the political feasibility of exclusion. Finally, perhaps more directly related to this paper's agenda, a direct empirical assessment of the implications of exclusion policies on income inequality across ethnic groups and on growth could be a natural follow up project.

\section{REFERENCES}

Acemoglu, D. and J. Robinson, 2000, "Why did the West extend the franchise? Democracy, inequality and growth in historical perspective," Quarterly Journal of Economics, 115, 1167-1199.

Bertocchi, G. and M. Spagat, 2001, "The politics of cooptation," Journal of Comparative Economics, 29, 591-607.

Bourguignon, F. and T. Verdier, 2000, "Oligarchy, democracy, inequality, and growth," Journal of Development Economics, 62, 285-313.

Caselli, F. and Coleman, W.J., 2002, "On the theory of ethnic conflict," mimeo.

Collier, P. and A. Hoeffler, 2001, "Greed and grievance in civil war," mimeo, World Bank.

Cutler, D.M. and E.L. Glaeser, 1997, “Are ghettos good or bad?" Quarterly Journal of Economics, 112, 827-872.

DiPasquale, D. and E. Glaeser, 1998, "The L.A. riot and the economics of urban unrest," Journal of Urban Economics, 43, 52-78.

Easterly, W., 2002, "The middle class consensus and economic development," mimeo, World Bank.

Easterly, W., 2001, “Can institutions resolve ethnic conflict?” Economic Development and Cultural Change, 49, 687-706.

Easterly, W. and R. Levine, 1997, "Africa's growth tragedy: Policies and ethnic divisions," Quarterly Journal of Economics, 112, 1203-1250.

Fryer, R.G., 2003, "An economic approach to cultural capital," mimeo.

Gellner, E., 1983, Nations and Nationalism, Ithaca, NY, Cornell University Press.

Glaeser, E. and Shleifer, A., 2002, "The Curley effect," NBER WP 8942.

Greenfeld, L., 1992, Nationalism: Five Roads to Modernity, Cambridge, MA, Harvard University Press.

Grossman, H., 1991, “A general equilibrium model of insurrections," American Economic Review, 81, 912-921. 
Gurr, T.R., 1993, Minorities at Risk: A Global View of Ethnopolitical Conflict, U.S. Institute of Peace Press.

Horowitz, D.J., 2001, Ethnic Groups in Conflict, updated edition, University of California Press.

Independent Commission on Migration to Germany, 2001, Structuring Immigration, Fostering Integration, http://www.bmi.bund.de/Annex

Jacobson, M.F., 1998, Whiteness of a Different Color: European Immigrants and the Alchemy of Race, Harvard University Press, Cambridge.

Klassen, S., 2002, "Social, economic and environmental limits for the newly enfranchised in South Africa," Economic Development and Cultural Change, 50, 607-642.

Mattoo, A. and Carzaniga, A. 2003. Moving People to Deliver Services.Oxford University Press for the World Bank. Washington, D.C.

Mazower, M., 1998, Dark Continent. Europe's Twentieth Century, Vintage Books, New York.

Patrinos, H.A., 1994, "The cost of ethnicity: International survey," in Patrinos, H.A. and G. Psacharopoulos, eds., Indigenous People and Poverty in Latin America, the World Bank.

Psacharopoulos, G., 1993, "Ethnicity, education and earnings in Bolivia and Guatemala," Comparative Education Review, 37, 9-20.

Rapoport, H. and A. Weiss, 2001, "The optimal size for a minority," IZA (Institute for the Study of Labor) DP 284, Bonn.

Reynal-Querol, M., 2002, "Ethnicity, political systems and civil wars," Journal of Conflict Resolution.

The Economist, February 21, 2004, "Indigenous people in South America. A political awakening," 35-37.

\section{APPENDIX}

Perfect exclusion

Maximization of the utility function of the minority members, for a given tax rate, yields:

$$
h_{2 t+1}=\alpha y_{2 t}(1-T) /(1+\alpha), c_{2 t}=y_{2 t}(1-T) /(1+\alpha), y_{2 t+1}=A\left[\alpha y_{2 t}(1-T) /(1+\alpha)\right]^{\alpha}
$$

and the utility level

$$
U_{2}=\ln \left(y_{2 t}(1-T) /(1+\alpha)\right)+\ln \left\{A\left[\alpha y_{2 t}(1-T) /(1+\alpha)\right]^{\alpha}\right\}
$$

while the values for the majority members are:

$$
c_{1 t}=y_{1 t}(1-T), y_{1 t+1}=A\left(T Y_{t} / N_{0}\right)^{\alpha}
$$

and the utility level 


$$
U_{l}=\ln \left\{y_{l t}(1-T)\right\}+\ln \left\{A\left(T Y_{t} / N_{0}\right)^{\alpha}\right\}
$$

The exploitative nature of ethnic interaction in this case becomes obvious once (A1) is compared with (A3). The comparison reveals that current consumption levels are higher for the majority in all periods, $t>0$; and next-period income levels are higher provided that the tax rate is not too small. As a result, comparing next-period utility levels (A2) and (A4) reveals that in this regard, too, the majority is better off when the tax rate is high enough.

From (A1), the steady state income level for the minority is

$$
y_{2}^{*}=A^{1 /(1-\alpha)}[\alpha(1-T) /(1+\alpha)]^{\alpha /(1-\alpha)}
$$

The steady state income level for the majority is then determined from:

$$
y_{1}^{*}=A\left(T N_{0}\right)^{\alpha} Y^{* \alpha}
$$

where

$$
Y^{*}=N_{0} y_{1}^{*}+\left(1-N_{0}\right) y_{2}^{*}
$$

is the average steady state income.

Differentiation reveals that (A7) is an increasing function of $N_{0}$ when it goes from $1 / 2$ to 1 , provided only that the tax rate is large enough.

\section{Perfect inclusion}

In this case, each individual's next-period income is $Y_{t+1}=A\left(T Y_{t}\right)^{\alpha}$, and the steady state income level is

$$
Y_{I}=A^{1 /(1-\alpha)} T^{\alpha /(1-\alpha)}
$$

Comparing with (A7), we observe that when $N_{0}=1$ the two are the same. Thus, when the tax rate is large enough so that (A8) increases in $N_{0}$ in the relevant range, steady state income level under inclusion is higher than that under exclusion.

The resulting next-period utility level is

$$
U\left(c_{i t}, y_{i t+1}\right)=\ln \left(y_{i t}(1-T)\right)+\ln \left\{A\left(T Y_{t}\right)^{\alpha}\right\}
$$


which is higher than under exclusion for all minority members and lower for all majority members.

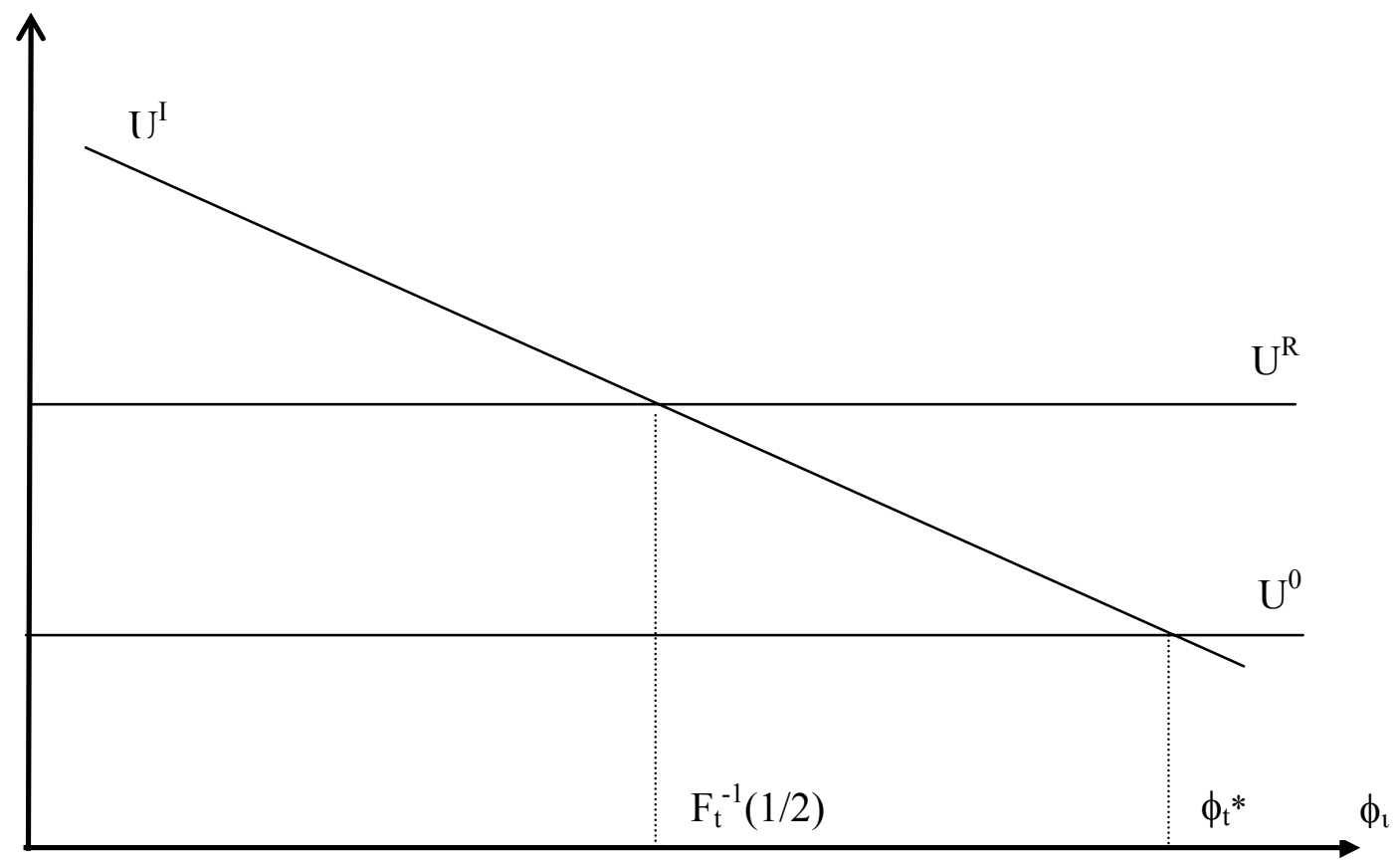

Figure 1 


\section{Endnotes}

${ }^{1}$ The substantive distinction between minority and majority groups in this paper is not so much in numerical terms as it is in terms of political influence.

${ }^{2}$ Mazower, 2002, contains a detailed account of mistreatment of ethnic minorities in Europe.

3 There are, of course, anectodal examples of highly successful discriminated minorities (Armenians in the Ottoman Empire, Indians in Africa, and Jews and Chinese almost everywhere), but they can hardly match the massive evidence of generally disadvantaged outcomes of other minority groups elsewhere.

${ }^{4}$ Discrimination in the provision of publicly provided goods to indigenous populations in Latin America is discussed at the end of Section 5.1.

5 See, e.g., the report of the Independent Commission on Migration to Germany, 2001, which recommends taking measures to foster the integration of immigrants.

${ }^{6}$ See, e.g., the following account: "In 1781, rebel Indian armies shook the foundations of the Spanish empire when they laid siege to this city [La Paz]... The siege of La Paz lasted 109 days, reducing the white population to eating rats and boiled shoe leather... Two centuries later, the memory of that uprising is haunting the Andean region - and inspiring its native Indian underclass to become powerful political players." (The Wall Street Journal, Class Struggle. Along the Andes, Indians Agitate for Political Gain," January 8, 2004).

${ }^{7}$ Depending on the intensity of the minority protest, its manifestation can be alternatively labeled as revolution, civil unrest, insurgency, or other.. And might well be the outcome of secession intentions as discussed below. We use "rebellion" without an attempt to distinguish among these forms of protest; the important element is that it entails loss of output, and that its distribution effect differs from that under peaceful accumulation.

${ }^{8}$ We do not address the fundamental issue of why ethnicity and not other characteristics serve so often as distinctive marks for exclusion and discrimination, as well as to facilitate collective action necessary for rebellion. But, clearly (and will hopefully become even more so when empirical evidence is discussed below) it is a salient feature with important empirical implications.

${ }^{9}$ The previous version of the paper considered endogenization of the choice of the tax rate; under the assumption that credible commitment to a tax rate is impossible, a constant rate emerges at the equilibrium.

10 See Bourguignon and Verdier, 2000, which explicitly focuses on how education promotes political participation.

${ }^{11}$ Note that, while in principle exclusion could be costly for the majority, here we disregard this element for simplicity.

12 Moreover, there is also an additional component related to the social pressures of the members of one's own group. Thus, in some Hispanic communities women in the United States are discouraged from pursuing higher education and some, better educated, African Americans are labeled by others as "acting white"; see Fryer, 2003, for a more detailed discussion.

${ }^{13}$ Note that we assume that the cost of cultural integration is only incurred when there are barriers to do so, that is when society distinguishes between ethnic groups. A more realistic assumption, that there is an additional psychological cost of cultural integration per se, would not significantly change the results.

${ }_{14}$ This is because of the assumption that integration costs are directly proportional to the level of exclusion; if there was an autonomous cost component, full integration would not necessarily take place, yet the main results would remain unchanged.

${ }^{15}$ Thus, this result contains both a normative component - that the economy may benefit in the long run from inclusion - and a positive one, that it is not in the best interest of the majority. One interpretation of this result is that a welfare improving policy of inclusion based on Coasean bargaining will not be realized because of incomplete contracting over the sharing of the resulting surplus.

${ }^{16}$ The analysis below ignores violent treatment of minority groups, such as ethnic cleansing or expulsion.

${ }^{17}$ Protest in the form of civil disobedience which leads to reallocation of the output in the indicated manner is also a possible interpretation of the model. A successful strike by the minority is another possible interpretation. The adopted interpretation in terms of violent confrontations is easier to relate to empirical findings, however. 
${ }^{18}$ Outbreaks of violence in the form of civil wars, rebellions, and civil unrest is a frequent by-product of interaction between ethnic groups, and they have been recently carefully documented in Gurr, 1993, and Horowitz, 2001. A review of these studies reveals that many of the violent confrontations are the result of discrimination against minorities - examples include riots and civil wars in Indonesia, parts of Central America (notably Guatemala and El Salvador), Northern Ireland, former Yugoslavia, the Kurdish resistance movement, and others. Moreover, many of these tragic struggles carry an enormous economic burden for all parties involved. The argument made in the ensuing analysis that accommodation of a minority can alleviate rebellion tendencies is related to Grossman, 1991, and Acemoglu and Robinson, 2000.

${ }^{19}$ This assumption is not necessary, but it significantly simplifies the analysis.

${ }^{20}$ See the characterization of the steady state under exclusion in the appendix.

${ }^{21}$ Although this paper's model does not address this issue explicitly, to the extent that segregation is associated with exclusion from consumption of higher quality education, the results are applicable.

${ }^{22}$ Indeed, a policy recommendation coming out of Patrinos, 1994, is that bilingual schooling could alleviate social exclusion.

${ }^{23}$ The following account is based on illuminating evidence summarized in Klasen, 2002.

${ }^{24}$ Incidentally, South Africa happens to be a society with one of the most unequal income distributions in the world, with the Gini coefficient of around 0.61 .

${ }^{25}$ This is the United Nations Development Program's (UNDP) composite measure of life expectancy, schooling achievement, and a transform of GDP per capita.

${ }^{26}$ For instance, past immigration from Burkina Faso and Mali to Cote d'Ivoire increased the size of the Moslem minority in the North of the country. 